\title{
Annona mucosa Jacq. (Annonaceae): A promising source of bioactive compounds against Sitophilus zeamais Mots. (Coleoptera: Curculionidae)
}

\author{
Leandro do Prado Ribeiro $^{\mathrm{a}, *}$, José Djair Vendramim ${ }^{\mathrm{a}}$, Keylla Utherdyany Bicalho ${ }^{\mathrm{b}}$, \\ Moacir dos Santos Andrade ${ }^{b}$, João Batista Fernandes ${ }^{b}$, Rafael de Andrade Moral ${ }^{c}$, \\ Clarice Garcia Borges Demétrio ${ }^{\mathrm{C}}$ \\ a Department of Entomology and Acarology, University of São Paulo/“Luiz de Queiroz” College of Agriculture (USP/ESALQ), Piracicaba, SP, Brazil \\ ${ }^{\mathrm{b}}$ Department of Chemistry, Federal University of São Carlos (UFSCar), São Carlos, SP, Brazil \\ ${ }^{\mathrm{C}}$ Department of Exact Sciences, University of São Paulo/“Luiz de Queiroz” College of Agriculture (USP/ESALQ), Piracicaba, SP, Brazil
}

\section{A R T I C L E I N F O}

\section{Article history:}

Accepted 4 June 2013

\section{Keywords:}

Maize weevil

Allelochemicals

Acetogenins

Alkaloids

Bioinsecticide

\begin{abstract}
A B S T R A C T
New control methods are necessary for stored grain pest management programs due to both the widespread problems of insecticide-resistance populations and the increasing concerns of consumers regarding pesticide residues in food products. Thus, this study evaluated the bioactivity of extracts and fractions obtained from different structures (leaves, branches, and seeds) of Annona mucosa (Annonaceae) against Sitophilus zeamais (Coleoptera: Curculionidae), which is a primary insect pest of stored cereals in tropical conditions. In the screening assay, the most promising treatments were extracts prepared from the seeds of Annona mucosa in hexane and dichloromethane ( $\mathrm{LC}_{90}$ values of 259.31 and $425.15 \mathrm{mg} \mathrm{kg}^{-1}$, respectively) and, to a lesser extent, an extract prepared from the leaves in hexane ( $\mathrm{LC}_{90}$ of $1047.15 \mathrm{mg} \mathrm{kg}^{-1}$ ). Based on these results and the chromatographic profile of the bioactive crude extracts, the extract prepared from the seeds in hexane was fractionated by liquid-liquid partitioning. The dichloromethane and hydroalcoholic fractions exhibited insecticidal activity against $S$. zeamais, and no significant difference was observed between these two fractions. The chemical analyses $\left({ }^{1} \mathrm{H}\right.$ NMR, HPLC, and TLC) showed the presence of alkaloids and acetogenins in the bioactive fractions, which are likely related to the observed bioactivity. Thus, A. mucosa, particularly its seeds, is a promising source of compounds that can be used as a prototype model and/or a biorational insecticide for the control of S. zeamais in stored cereals.
\end{abstract}

Crown Copyright $\odot 2013$ Published by Elsevier Ltd. All rights reserved.

\section{Introduction}

In tropical countries, especially those with developing economies, post-harvest grain losses are very significant (Basavaraja et al., 2007; Hodges et al., 2010; Olayemi et al., 2012; Tefera, 2012). Infestations caused by stored grain insect pests is a major cause of these losses; these infestations are mainly due to climatic conditions that favor the development of these biota and the unsatisfactory conditions of the storage infrastructure (Lazzari and Lazzari, 2009), which enable the constant re-infestation of the

\footnotetext{
* Corresponding author. Department of Entomology and Acarology, University of São Paulo/“Luiz de Queiroz” College of Agriculture (USP/ESALQ), Av. Pádua Dias, 11, Agronomia, CEP 13418-900, Piracicaba, São Paulo, Brazil. Tel.: +55 1933753714.

E-mail addresses: lpribeiro@usp.br, leandro_universidade@hotmail.com (L.doP. Ribeiro).
}

stored grain and undermine the effectiveness of management programs.

The structural and technological limitations inherent in the management of insect pests of stored grains are usually accompanied by an increased frequency of the use of synthetic insecticide applications, which is the main method for the management of these insect pests. This increase in insecticide use leads to greater selection pressure and an increase in the number of populations that are resistant to the insecticidal active ingredients (Pereira et al., 2009; Pimentel et al., 2009; Rofrano et al., 2009; Araújo et al., 2011; Braga et al., 2011). This effect is compounded by the limited availability of registered insecticides, which complicates the management of insect resistant populations through the alteration of the active ingredients (Boyer et al., 2012). The post-harvest losses are thereby increased, and the investments made in the previous stages of the production process, as well as 
the agricultural sustainability, are jeopardized (Ribeiro et al., 2008).

It is thus necessary to incorporate new substances that meet the requirements of agronomic efficiency, toxicological safety, and low environmental impact (Viegas Júnior, 2003) into programs for the integrated management of the insect pests of stored grains (IPM). The identification of compounds with modes/mechanisms of action that are different from those that are found in the currently used insecticides (which are mostly neurotoxic) is also desirable, especially for the management of resistant populations of these pests in the storage units.

Plants produce a diverse range of allelochemicals that regulate insect-plant interactions, especially in the defense of the plant against herbivory (Van Beek and Breteler, 1993; Cloyd, 2004; Isman, 2006). Thus, these allelochemicals constitute an important source of insecticide molecules that can be applied in an integrated management program (IPM) against the insect pests of stored grain through two methods: the preparation of homemade insecticides from locally available species for direct use on the property, which contributes to the reduction of the technological dependence of farms (this is particularly true for small farms), and as model prototypes for the development of new synthetic insecticides (Vendramim and Castiglioni, 2000).

Annonaceae is one of the largest families of angiosperms; to date, it includes 135 genera and approximately 2500 species (Chatrou et al., 2004). However, despite its great diversity, this family is one of the lesser studied tropical plant families from the phytochemical viewpoint. The studies conducted to date have demonstrated the presence of a large amount of diverse chemical compounds in the different species and structures of this family (Leboeuf et al., 1980; Chang et al., 1998; Kotkar et al., 2001).

Among the Neotropical Annonaceae, Annona mucosa Jacq. (formerly grouped in the genus Rollinia (Rainer, 2007)) is a native fruit tree of the Amazon and the Atlantic forest that is popularly known as "biribá". Although Brazil is its place of origin, this species grows well in different habitats (Ferreira et al., 2010). Pharmacological and phytochemical studies have revealed the presence of acetogenins (Pettit et al., 1987; Shi et al., 1996, 1997; Gu et al., 1997; Chávez et al., 1998,1999; Liaw et al., 2003), alkaloids (Caetano and Dadoun, 1987; Chen et al., 1996), amides (Chávez et al., 1999), and lignans (Chen et al., 1996; Figueiredo et al., 1999; Estrada-Reyes et al., 2002) as major constituents of different A. mucosa structures. A number of compounds isolated from this species have shown antimicrobial, antifungal, antiprotozoal, and antitumor potential (Caetano and Dadoun, 1987; Shi et al., 1996; Gu et al., 1997; Chávez et al., 1999; Liaw et al., 2003), which has generated interest in the assessment of the potential of $A$. mucosa derivatives as a source of allelochemicals with insecticidal properties that could be used in the management of the pest species of economically important stored grain. Thus, the objective of the present study was to evaluate the bioactivity of organic extracts and fractions obtained from different $A$. mucosa structures against Sitophilus zeamais Motschulsky (Coleoptera: Curculionidae), which is the main pest species of stored cereals in tropical conditions.

\section{Material and methods}

\subsection{Vegetation samples and preparation of crude extracts}

The leaves, branches, and seeds of $A$. mucosa that were used in the study were obtained on January 22, 2010, from a specimen grown in the "Luiz de Queiroz" College of Agriculture/University of São Paulo (ESALQ/USP) in Piracicaba, SP, Brazil (latitude: $22^{\circ} 42^{\prime}$ $26^{\prime \prime}$ S; longitude: $47^{\circ} 37^{\prime} 39^{\prime \prime} \mathrm{W}$ ). A voucher specimen was deposited in the herbarium of the "Luiz de Queiroz" College of Agriculture
(Herbarium ESA) in Piracicaba, SP, Brazil, under reference number 120985.

To prepare the extracts, the collected plant parts were dried in an oven at $38{ }^{\circ} \mathrm{C}$ for $48-72 \mathrm{~h}$. Subsequently, the materials were separately milled in a knife mill to obtain a powder of each plant structure, which was stored separately in sealed glass containers until use.

The organic extracts were obtained by cold maceration using solvents $(5: 1, \mathrm{v} / \mathrm{w})$ with increasing polarity: hexane ( polarity $=0.06)$, dichloromethane (polarity = 3.4), and ethanol (polarity = 5.2). The extraction in each solvent was performed until exhaustion, after which the solvent with the next higher polarity was used. During each solvent change, the macerate was filtered through filter paper, the solvent was removed from the sample, and the sample was maintained in a rotary evaporator at a temperature of $40{ }^{\circ} \mathrm{C}$ and a pressure of $-600 \mathrm{~mm} \mathrm{Hg}$. After the complete evaporation of the solvent in an air-flow chamber, the extraction yield for each plant structure in each of the different solvents was determined.

\subsection{Bioassays}

All of the bioassays were conducted at a room temperature of $25 \pm 2{ }^{\circ} \mathrm{C}$, with a relative humidity (RH) of $60 \pm 10 \%$, a 14 -h photoperiod, and an average luminosity of 172 lux. Whole corn grains (hybrid AG 1051: yellow-toothed, semi-hard) were used as the test substrate. The grains were selected manually from a crop grown without the use of insecticides. Before use, the grains were maintained in a climate-controlled room under the conditions described above for a minimum of 30 days to equilibrate the moisture content (grain humidity was approximately $12.5 \pm 0.5 \%$ ).

Prior to the definitive assays, preliminary bioassays (Ribeiro, 2010) were conducted to determine the solution volume that should be used, to verify the uniformity of the application of the extracts in the grains, and to assess the possible effects of the organic solvents used in the resuspension of the plant extracts and fractions on S. zeamais.

To identify the extracts that exhibit bioactive effects on S. zeamais, bioassays were conducted to determine the insecticidal activity of the extracts and to assess their effect on the F1 progeny of $S$. zeamais and the damage to the corn. The extracts were applied at concentrations of 300 and $1500 \mathrm{mg} \mathrm{kg}^{-1}$ (mg of extract per $\mathrm{kg}$ of corn), which were defined based on previous studies, on samples of corn grains through the aid of a microatomizer coupled to a pneumatic pump and adjusted to provide a pressure of $0.5 \mathrm{kgf} \mathrm{cm}^{-2}$ using a spray volume of $30 \mathrm{~L} \mathrm{t}^{-1}$. After the spraying, the grainextract mixtures were manually collected in 2 -L plastic bags, which were then stirred for $1 \mathrm{~min}$ and maintained for $2 \mathrm{~h}$ in an airflow chamber to evaporate the solvent that was used for the resuspension of the extracts.

\subsubsection{Evaluation of insecticidal activity}

In this bioassay, Petri dishes (6- $\mathrm{cm}$ diameter and 2-cm high) containing 10-g samples of corn were used. These Petri dishes were treated separately with the respective plant extract or the control growth substrate that consisted of the solvent used in the respective extract resuspension. Each sample unit was then infested with 20 (unsexed) S. zeamais adults aged between 10 and 20 days that were obtained from a laboratory-reared population; 10 replicates of each treatment were performed. The adult survival was assessed on the 10 th day after the infestation. Those individuals with completely distended wings and that showed no reaction to contact with a brush during $1 \mathrm{~min}$ of observation were considered dead.

The same sampling units from the previous test were used in the bioassay to assess progeny production and resulting damage. In this assay, the grains were treated with the respective extracts and 
infested with 20 (unsexed) S. zeamais adults aged between 10 and 20 days. After 10 days of infestation, the adults were removed, and the sample units maintained under the climatic conditions described above. Similarly to the previous bioassay, 10 replicates of each treatment were performed.

Sixty days after the initial infestation, the number of emerging adults on each plate was counted. At the same time, the damage caused by $S$. zeamais feeding was estimated by determining the percentage of grains that were damaged or punctured in each sample plate through the visual evaluation of each grain. Subsequently, the grain weight loss (\%) was estimated based on the equation proposed by Adams and Schulten (1976):

$\operatorname{Lw}(\%)=(N d g / N \operatorname{tg}) 100 C$

where $L \mathrm{w}$ is the weight loss (\%), $N d g$ is the number of damaged grains, $N$ tg is the number of total grains, and $\mathrm{C}$ is a constant that is equal to 0.125 if the maize is stored as loose grains or on the cob without bracts or 0.222 if the maize is stored on the cob with bracts.

The extracts that exhibited the most promising results were tested to estimate the $\mathrm{LC}_{50}$ and $\mathrm{LC}_{90}$, which are the concentrations required to kill 50 and $90 \%$ of the weevil population, respectively. To estimate these concentrations, preliminary tests were performed with the extracts to determine the concentrations that caused a $95 \%$ adult mortality and a mortality level similar to that obtained in the control. Based on these concentrations, the test concentrations were determined using the formula proposed by Finney (1971). The remaining experimental procedures were the same as those used in the initial screening, in which the mortality was assessed 10 days after the infestation of the sample units.

\subsection{Fractionation of the most promising extract and analysis and bioassay of the fractions}

The most promising extract was selected and subjected to fractionation to determine the classes of compounds present in the bioactive fractions. The bioactive fractions were determined based on the results of biological assays, the determination of the extraction yield, and the evaluation of the chromatographic profile, which was obtained through thin-layer chromatography (TLC) using a hexane and acetone (hexane:acetone volume ratio of 3:2) solution as the eluent and visualized using a vanillin sulfuric solution.

The selected extract was resuspended in a mixture of methanol and water (methanol:water volume ratio of $1: 3$ ) and subjected to liquid-liquid partitioning using a separating funnel and organic solvents with increasing polarity to obtain the hexane, dichloromethane, and hydroalcoholic fractions. The formation of a suspension that was difficult to separate made it impossible to obtain other partitions with intermediate polarities. The partitions (fractions) obtained were then concentrated in a rotary evaporator under the same temperature and pressure conditions used to produce the crude extracts. These fractions were also analyzed by hydrogen nuclear magnetic resonance ( ${ }^{1} \mathrm{H}$ NMR) in a Bruker DRX 400 (9.4 T) instrument using the deuterated solvents $\mathrm{CDCl}_{3}$ and DMSO- $\mathrm{d}_{6}$.

After the fractions were obtained and analyzed, the effect of the fractions on the survival of S. zeamais adults was evaluated. Samples of corn grains $(10 \mathrm{~g})$ were treated with these fractions using the same experimental protocol that was used for the initial screening. The mortality of the adults exposed to the respective fractions was evaluated as described in Section 2.2.1.

\subsection{Analysis of the chemical classes of bioactive fractions}

To identify the proportions that were best suited for the separation of the sample components, the selected bioactive fractions of the extract were analyzed by TLC using eluents of varying polarity: hexane and acetone (hexane:acetone volume ratio of $3: 1$ ), hexane and acetone (hexane:acetone volume ratio of $3: 2$ ), hexane and dichloromethane (hexane:dichloromethane volume ratio of 1:3), and dichloromethane (100\%). In addition to the developer solution of vanillin sulfuric, the visualization of the results was also performed through the use of ultraviolet light $(254 \mathrm{~nm}$ ) and the Kedde and Dragendorff reagents, the latter of which specifically identifies alkaloids. The chemical analysis of the profiles of the bioactive fractions was performed through high-performance liquid chromatography (HPLC) with an exploratory elution gradient using a chromatograph (model 1200, Agilent Technologies) equipped with a G1311A quaternary pump, a G1322A degasser, a G1329A autosampler, and a G1314B UV detector. The equipment was connected to a G1369A interface, and the chromatograms were recorded using the EZCHrom Elite software. The following injection conditions were adopted for the analysis:

Sample concentration: [ ] $=100 \mu \mathrm{g} / \mathrm{mL}$.

Injection volume: $V_{\text {inj }}=20 \mu \mathrm{L}$.

Chromatographic column: Eclipse XDB-C18 $5 \mu \mathrm{m}(150 \times 4.60 \mathrm{~mm})$ Chromatographic conditions: $10 \% \mathrm{MeOH}$ and $90 \% \mathrm{H}_{2} \mathrm{O}$ for $5 \mathrm{~min}$, then $50 \% \mathrm{MeOH}$ and $50 \% \mathrm{H}_{2} \mathrm{O}$ for $15 \mathrm{~min}$, and then $95 \% \mathrm{MeOH}$ and $5 \% \mathrm{H}_{2} \mathrm{O}$ for $10 \mathrm{~min}$ and for an additional $10 \mathrm{~min}$.

\subsection{Data analysis}

In general, the count and proportion data have been analyzed by fitting the binomial and Poisson generalized linear models, respectively (Nelder and Wedderburn, 1972). It is expected that the residual deviance (a measure of the model fit) of a well-fitted model is approximately equal to the residual degrees of freedom. If this is not the case, it is possible that the variation may simply be greater than the variation that is expected by the model; this phenomenon is called overdispersion (Hinde and Demétrio, 1998). If the residual deviance is approximately equal to the residual degrees of freedom, then the model parameters can be estimated using the quasi-likelihood method. These models, which are known as quasi-Poisson and quasi-binomial, were used to analyze the counts of the emerged insects and the proportion of damaged grains, respectively. The proportions of the mortality data were analyzed using a binomial generalized linear model (GLM). The fit of the GLM was determined using the half-normal probability plot with a simulation envelope (Demétrio and Hinde, 1997). All of the analyses were performed using the " $R$ " statistical software, version 2.13.1 (R Development Core Team, 2012).

The estimates of the lethal concentrations were obtained through a Probit analysis (Finney, 1971) using the Poloplus 1.0 program (Leora Software, 2003).

\section{Results}

The most pronounced bioactive effects on $S$. zeamais, which were observed on all of the variables, were obtained with the use of the extracts produced from the seeds of $A$. mucosa (Tables 1-3). However, the response levels obtained were dependent on both the extract concentration and the organic solvent that was used in the production of the extract.

The seed extracts of $A$. mucosa obtained using hexane and dichloromethane as the solvent exhibited the most pronounced effects on S. zeamais; these effects were determined based on the analyzed variables (Tables 1 and 2). A $300 \mathrm{mg} \mathrm{kg}^{-1}$ concentration of these extracts caused substantial weevil mortality and almost completely inhibited the F1 progeny, which drastically reduced the damage to the corn samples. The highest concentration of these two extracts ( $1500 \mathrm{mg} \mathrm{kg}^{-1}$ ) resulted in the complete mortality of 
Table 1

Mean ( \pm standard error) mortality of Sitophilus zeamais adults after 10 days of treatment, the number of emerged insects (F1 progeny) after 60 days of treatment, and the damage to the grain after 60 days of infestation by Sitophilus zeamais. These variables were assessed in corn samples $(10 \mathrm{~g})$ that were treated with two different concentrations $s^{\mathrm{f}}$ of extracts that were prepared from different parts of Annona mucosa in hexane. Temperature: $25 \pm 2{ }^{\circ} \mathrm{C}$; $\mathrm{RH}$ : $60 \pm 10 \%$; photophase: $14 \mathrm{~h}$; mean illuminance: 172 lux.

\begin{tabular}{|c|c|c|c|c|c|}
\hline \multirow{2}{*}{$\begin{array}{l}\text { Plant } \\
\text { part }\end{array}$} & \multirow[t]{2}{*}{ Mortality (\%) } & \multirow{2}{*}{$\begin{array}{l}\text { No. of emerged } \\
\text { insects }^{b}\end{array}$} & \multirow{2}{*}{$\begin{array}{l}\text { \% Grains } \\
\text { damaged }^{c}\end{array}$} & \multicolumn{2}{|c|}{ Grain weight loss } \\
\hline & & & & Total $(\%)^{\mathrm{d}}$ & Relative $^{\mathrm{e}}$ \\
\hline \multicolumn{6}{|c|}{$300 \mathrm{mg} \mathrm{kg}^{-1}$} \\
\hline Seeds & $98.00 \pm 1.10 \mathrm{a}$ & $0.80 \pm 0.32 b$ & $3.60 \pm 1.07 \mathrm{~b}$ & 0.45 & 4.06 \\
\hline Leaves & $0.50 \pm 0.50 \mathrm{~b}$ & $38.60 \pm 2.70 \mathrm{a}$ & $90.92 \pm 1.85 a$ & 11.35 & 102.52 \\
\hline Branches & $1.50 \pm 0.76 b$ & $34.70 \pm 3.25 \mathrm{a}$ & $81.01 \pm 6.71 \mathrm{a}$ & 10.10 & 91.23 \\
\hline Control & $0.00 \pm 0.00$ & $36.90 \pm 2.66 \mathrm{a}$ & $88.61 \pm 1.68 a$ & 11.07 & 100.00 \\
\hline $1500 \mathrm{mg}$ & $\begin{array}{l}\chi^{2}: 22.31 \\
P:<0.0001 \\
\mathbf{k g}^{-\mathbf{1}}\end{array}$ & $\begin{array}{l}F: 91.46 \\
P:<0.0001\end{array}$ & $\begin{array}{l}F: 211.57 \\
P:<0.0001\end{array}$ & - & - \\
\hline Seeds & $100.00 \pm 0.00$ & $0.00 \pm 0.00$ & $0.00 \pm 0.00$ & 0.00 & 0.00 \\
\hline Leaves & $61.50 \pm 6.50 a$ & $5.60 \pm 1.83 b$ & $22.39 \pm 4.92 b$ & 2.80 & 26.49 \\
\hline Branches & $0.00 \pm 0.00$ & $39.10 \pm 2.52 \mathrm{a}$ & $91.75 \pm 2.00 \mathrm{a}$ & 11.47 & 108.51 \\
\hline Control & $\begin{array}{l}0.00 \pm 0.00 \\
\chi^{2}: 29.59 \\
P:<0.0001\end{array}$ & $\begin{array}{l}37.00 \pm 4.74 \text { a } \\
F: 36.26 \\
P:<0.0001\end{array}$ & $\begin{array}{l}84.76 \pm 4.97 a \\
F: 51.91 \\
P:<0.0001\end{array}$ & $\begin{array}{l}10.57 \\
-\end{array}$ & $\begin{array}{l}100.00 \\
-\end{array}$ \\
\hline
\end{tabular}

a The means that are followed by the same letter in this column (for each concentration) are not significantly different according to the confidence intervals of the means obtained by the binomial generalized linear model $(P \geq 0.05)$.

b The means that are followed by the same letter in this column (for each concentration) are not significantly different according to the confidence intervals of the means obtained by the quasi-Poisson generalized linear model $(P \geq 0.05)$.

${ }^{c}$ The means that are followed by the same letter in this column (for each concentration) are not significantly different according to the confidence intervals of the means obtained by the quasi-binomial generalized linear model $(P \geq 0.05)$.

d Calculated using the formula developed by Adams and Schulten ${ }^{36}$.

e Calculated based on the relative comparison of the treatment (extract) with the respective control.

${ }^{\mathrm{f}}$ In a solution volume of $30 \mathrm{~L} \mathrm{t}^{-1}$.

the weevils that were exposed to grains treated with either of the extracts. In addition, a complete inhibition of the F1 progeny was observed with the highest concentration of the extract prepared using hexane. Moreover, the estimated lethal concentrations ( $\mathrm{LC}_{50}$ and $\mathrm{LC}_{90}$ ) of these two extracts did not show any significant differences based on a comparison of the confidence intervals obtained ( $P \geq 0.05$, Table 4$)$. These results therefore corroborate the similarities observed in the chemical profiles of the two extracts, which were obtained by TLC analysis. The extract of $A$. mucosa seeds that was prepared with ethanol exhibited significant bioactive effects on all of variables (Table 3 ) but at levels that were less significant than those obtained with the more apolar extracts (hexane and dichloromethane). This finding provides preliminary evidence that the chemical nature of the active compounds is of low to medium polarity.

The analysis of the extracts obtained from the A. mucosa leaves exhibited significant effects only with the highest concentration $\left(1500 \mathrm{mg} \mathrm{kg}{ }^{-1}\right)$ of the extract that was prepared using hexane as the solvent (Table 1 ). However, this effect was less pronounced than that obtained with the extracts produced from the $A$. mucosa seeds, as reflected in the estimated lethal concentrations (Table 4). Purification procedures of these extracts may concentrate the active ingredient(s) and, thus, reduce the required amount to be applied in order to obtain the desired lethal effect.

Considering the results obtained in the screening and evaluation of the extract chemical profiles by TLC analysis, the hexane extract of the A. mucosa seeds was selected for fractionation to determine the classes of compounds that are present in the bioactive fractions. Thus, the hexane extract of the seeds was subjected to a liquidliquid partitioning, which generated hexane, dichloromethane, and hydroalcoholic fractions that were again tested against the maize
Table 2

Mean ( \pm standard error) mortality of Sitophilus zeamais adults after 10 days of treatment, the number of emerged insects (F1 progeny) after 60 days of treatment, and the damage to the grain after 60 days of infestation by Sitophilus zeamais. These variables were assessed in corn samples $(10 \mathrm{~g})$ that were treated with two different concentrations $^{\mathrm{f}}$ of extracts that were prepared from different parts of Annona mu$\cos a$ in dichloromethane. Temperature: $25 \pm 2{ }^{\circ} \mathrm{C}$; RH: $60 \pm 10 \%$; photophase: $14 \mathrm{~h}$; mean illuminance: 172 lux.

\begin{tabular}{|c|c|c|c|c|c|}
\hline \multirow{2}{*}{$\begin{array}{l}\text { Plant } \\
\text { part }\end{array}$} & \multirow[t]{2}{*}{ Mortality (\%) ${ }^{\mathrm{a}}$} & \multirow{2}{*}{$\begin{array}{l}\text { No. of emerged } \\
\text { insects }^{\text {b }}\end{array}$} & \multirow{2}{*}{$\begin{array}{l}\% \text { Grains } \\
\text { damaged }^{\mathrm{c}}\end{array}$} & \multicolumn{2}{|c|}{ Grain weight loss } \\
\hline & & & & Total (\%) $)^{\mathrm{d}}$ & Relative $^{\mathrm{e}}$ \\
\hline \multicolumn{6}{|c|}{$300 \mathrm{mg} \mathrm{kg}^{-1}$} \\
\hline Seeds & $85.50 \pm 2.92 \mathrm{a}$ & $1.10 \pm 0.40 \mathrm{~b}$ & $7.84 \pm 1.02 b$ & 0.97 & 9.46 \\
\hline Leaves & $1.00 \pm 0.66 \mathrm{~b}$ & $31.30 \pm 3.06 \mathrm{a}$ & $81.97 \pm 5.95 a$ & 10.21 & 99.60 \\
\hline Branches & $0.00 \pm 0.00$ & $29.90 \pm 2.97 \mathrm{a}$ & $83.71 \pm 3.81 \mathrm{a}$ & 10.44 & 101.85 \\
\hline Control & $0.00 \pm 0.00$ & $31.50 \pm 2.50 \mathrm{a}$ & $81.94 \pm 3.26 a$ & 10.25 & 100.00 \\
\hline $1500 \mathrm{mg}$ & $\begin{array}{l}\chi^{2}: 18.41 \\
P:<0.0001 \\
\mathbf{k g}^{-1}\end{array}$ & $\begin{array}{l}F: 62.66 \\
P:<0.0001\end{array}$ & $\begin{array}{l}F: 58.97 \\
P:<0.0001\end{array}$ & - & - \\
\hline Seeds & $100.00 \pm 0.00$ & $0.10 \pm 0.10 b$ & $1.12 \pm 0.61 \mathrm{c}$ & 0.14 & 1.37 \\
\hline Leaves & $4.00 \pm 2.56 a$ & $19.60 \pm 2.70 \mathrm{a}$ & $57.90 \pm 6.42 b$ & 7.24 & 71.11 \\
\hline Branches & $0.00 \pm 0.00$ & $22.50 \pm 2.51 \mathrm{a}$ & $64.97 \pm 5.64 \mathrm{ab}$ & 8.09 & 79.46 \\
\hline Control & $\begin{array}{l}0.00 \pm 0.00 \\
\chi^{2}: 23.74 \\
P:<0.0001\end{array}$ & $\begin{array}{l}30.20 \pm 3.74 \mathrm{a} \\
F: 46.78 \\
P:<0.0001\end{array}$ & $\begin{array}{l}81.74 \pm 4.63 a \\
F: 48.08 \\
P:<0.0001\end{array}$ & $\begin{array}{l}10.18 \\
-\end{array}$ & $\begin{array}{l}100.00 \\
-\end{array}$ \\
\hline
\end{tabular}

a The means that are followed by the same letter in this column (for each concentration) are not significantly different according to the confidence intervals of the means obtained by the binomial generalized linear model $(P \geq 0.05)$.

b The means that are followed by the same letter in this column (for each concentration) are not significantly different according to the confidence intervals of the means obtained by the quasi-Poisson generalized linear model $(P \geq 0.05)$.

${ }^{c}$ The means that are followed by the same letter in this column (for each concentration) are not significantly different according to the confidence intervals of the means obtained by the quasi-binomial generalized linear model $(P \geq 0.05)$.

${ }^{d}$ Calculated using the formula developed by Adams and Schulten ${ }^{36}$.

e Calculated based on the relative comparison of the treatment (extract) with the respective control.

${ }^{\mathrm{f}}$ In a solution volume of $30 \mathrm{~L} \mathrm{t}^{-1}$.

weevil. The results of this bioassay showed significant mortality of the weevils exposed to the dichloromethane and hydroalcoholic fractions (Fig. 1); the mortality rates associated with these fractions were found to be statistically similar. A concentration of the active compounds was also observed in these fractions because both caused mortalities that were far superior to those obtained with the crude extract ( $\mathrm{LC}_{50}$ of the fractions tested in the respective extract).

The HPLC analysis of the active fractions (dichloromethane and hydroalcoholic) of the hexane extract produced from the A. mucosa seeds was performed using an exploratory gradient. This analysis provided similar chromatographic profiles for the two samples (Fig. 2). In fact, both the peaks of the major compounds and the abundance of the substances in each fraction were similar, which indicates that there are significant similarities in their chemical compositions. This result confirms the behavior that was observed in the biological assays with $S$. zeamais, which showed no significant difference between these fractions. However, the chromatographic profiles only allow for a comparison between fractions and do not provide evidence of the classes of compounds that are present in these fractions. Therefore, ${ }^{1} \mathrm{H}$ NMR and TLC analyses were used to identify the principal classes of compounds in the samples. In general, ${ }^{1} \mathrm{H}$ NMR data are sufficient to provide the chemical composition of a sample. Furthermore, the combination of this technique with multidimensional analysis typically allows for the identification of the substances present in crude extracts (Kim et al., 2010). In the present study, the ${ }^{1} \mathrm{H}$ NMR analysis enabled the simultaneous determination of the classes of compounds present in the fractions studied Figs. 3 and 4.

Based on the interpretation of the signals with different chemical shifts that were observed in the ${ }^{1} \mathrm{H}$ NMR spectrum of the hexane fraction of the extract prepared from the $A$. mucosa seeds using 
Table 3

Mean ( \pm standard error) mortality of Sitophilus zeamais adults after 10 days of treatment, the number of emerged insects (F1 progeny) after 60 days of treatment, and the damage to the grain after 60 days of infestation by Sitophilus zeamais. These variables were assessed in corn samples $(10 \mathrm{~g})$ that were treated with two different concentrations $s^{\mathrm{f}}$ of extracts that were prepared from different parts of Annona mucosa in ethanol. Temperature: $25 \pm 2{ }^{\circ} \mathrm{C}$; $\mathrm{RH}$ : $60 \pm 10 \%$; photophase: $14 \mathrm{~h}$; mean illuminance: 172 lux.

\begin{tabular}{|c|c|c|c|c|c|}
\hline \multirow{2}{*}{$\begin{array}{l}\text { Plant } \\
\text { part }\end{array}$} & \multirow[t]{2}{*}{ Mortality (\%) } & \multirow{2}{*}{$\begin{array}{l}\text { No. of emerged } \\
\text { insects }^{\text {b }}\end{array}$} & \multirow{2}{*}{$\begin{array}{l}\text { \% Grains } \\
\text { damaged }^{\mathrm{c}}\end{array}$} & \multicolumn{2}{|c|}{ Grain weight loss } \\
\hline & & & & Total (\%) & Relative $^{\mathrm{e}}$ \\
\hline \multicolumn{6}{|c|}{$300 \mathrm{mg} \mathrm{kg}^{-1}$} \\
\hline Seeds & $16.50 \pm 3.57 \mathrm{a}$ & $7.60 \pm 2.21 b$ & $31.32 \pm 5.96 b$ & 3.92 & 45.37 \\
\hline Leaves & $0.50 \pm 0.50 \mathrm{~b}$ & $24.40 \pm 2.70 \mathrm{a}$ & $69,33 \pm 3.41 \mathrm{a}$ & 8.70 & 100.69 \\
\hline Branches & $0.50 \pm 0.50 \mathrm{~b}$ & $28.00 \pm 1.98 \mathrm{a}$ & $79.13 \pm 3.24 \mathrm{a}$ & 9.89 & 114.46 \\
\hline Control & $0.00 \pm 0.00$ & $21.00 \pm 2.57 \mathrm{a}$ & $69.16 \pm 5.81 \mathrm{a}$ & 8.64 & 100.00 \\
\hline 1500 & $\begin{array}{l}\chi^{2}: 31.66 \\
P:<0.0001\end{array}$ & $\begin{array}{l}F: 13.158 \\
P:<0.0001\end{array}$ & $\begin{array}{l}F: 14.36 \\
P:<0.0001\end{array}$ & - & - \\
\hline \multicolumn{6}{|c|}{$1500 \mathrm{mg} \mathrm{kg}^{-1}$} \\
\hline Seeds & $33.0 \pm 7.15 \mathrm{a}$ & $6.60 \pm 1.15 b$ & $38.60 \pm 7.04 b$ & 4.82 & 40.74 \\
\hline Leaves & $0.00 \pm 0.00$ & $35.70 \pm 2.99 \mathrm{a}$ & $87.16 \pm 2.51 \mathrm{a}$ & 10.90 & 92.13 \\
\hline Branches & $0.00 \pm 0.00$ & $42.40 \pm 2.68 \mathrm{a}$ & $92.24 \pm 1.71 \mathrm{a}$ & 11.54 & 97.54 \\
\hline Control & $\begin{array}{l}0.50 \pm 0.50 b \\
\chi^{2}: 46.68 \\
P:<0.0001\end{array}$ & $\begin{array}{l}37.20 \pm 2.19 \text { a } \\
F: 59.92 \\
P:<0.0001\end{array}$ & $\begin{array}{l}94.61 \pm 1.60 \mathrm{a} \\
F: 42.04 \\
P:<0.0001\end{array}$ & $\begin{array}{l}11.83 \\
-\end{array}$ & $\begin{array}{l}100.00 \\
-\end{array}$ \\
\hline
\end{tabular}

a The means that are followed by the same letter in this column (for each concentration) are not significantly different according to the confidence intervals of the means obtained by the binomial generalized linear model $(P \geq 0.05)$.

b The means that are followed by the same letter in this column (for each concentration) are not significantly different according to the confidence intervals of the means obtained by the quasi-Poisson generalized linear model $(P \geq 0.05)$.

c The means that are followed by the same letter in this column (for each concentration) are not significantly different according to the confidence intervals of the means obtained by the quasi-binomial generalized linear model $(P \geq 0.05)$.

d Calculated using the formula developed by Adams and Schulten.

e Calculated based on the relative comparison of the treatment (extract) with the respective control.

${ }^{\mathrm{f}}$ In a solution volume of $30 \mathrm{~L} \mathrm{t}^{-1}$.

hexane (Fig. 2A), it was possible to determine that this fraction was composed mainly of triglycerides, which are triacylglycerols in which each ester group contains a hydrocarbon chain (saturated or not saturated). Thus, the spectrum exhibits signals with chemical shifts at 4.04, 4.25, and $5.20 \mathrm{ppm}$, which are characteristic of the hydrogens of oxymethine carbons, and between $2.22 \mathrm{ppm}$ and $2.68 \mathrm{ppm}$, which are characteristic of $\alpha$ and $\beta$-carboxylic hydrogens, respectively. The presence of alkyl chains linked to ester groups is shown by the presence of signals with shifts that range between 0.78 and $1.23 \mathrm{ppm}$, which indicate methyl and methylene groups, respectively. The presence of unsaturated chains was also observed because the observed signals with chemical shifts between 5.18 and 5.30 ppm and between 1.91 and 1.99 are characteristic of hydrogens with double bonds and methylene groups neighboring these double bonds, respectively.

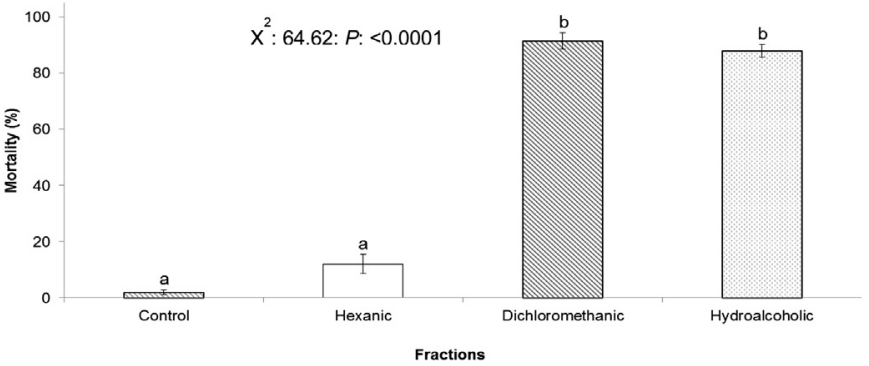

Fig. 1. Percentage of mortality ( \pm standard error) of Sitophilus zeamais adults exposed to corn samples $(10 \mathrm{~g})$ that were treated with fractions of the extract prepared from the seeds of Annona mucosa in hexane. The fractions were added at a concentration equal to the $\mathrm{LC}_{50}$ that was estimated for the respective crude extract. The mortality was assessed after 10 days of treatment. Temperature: $25 \pm 2{ }^{\circ} \mathrm{C}$; $\mathrm{RH}: 60 \pm 10 \%$; photophase: $14 \mathrm{~h}$; mean illuminance: 172 lux. The bars that are followed by the same letter are not significantly different according to the confidence intervals of the means obtained by the binomial generalized linear model $(P \geq 0.05)$.

The same set of signals that characterizes the presence of triglycerides in the ${ }^{1} \mathrm{H}$ NMR spectrum of the hexane fraction was also observed in the spectrum of the dichloromethane fraction of the extract prepared from the A. mucosa seeds using hexane (Fig. 2B). In addition, signals were observed with chemical shifts of between 6.5 and $7.4 \mathrm{ppm}$, which can indicate either the presence of alkaloids and thus aromatic hydrogens or the presence of acetogenins, which are related to the hydrogens of the double bond in the lactone ring structure of the acetogenins in Annonaceae (usually observed in the range between 6.8 and $7.1 \mathrm{ppm}$ ). Signals with chemical shifts in this same range were also observed in the ${ }^{1} \mathrm{H}$ NMR spectrum of the hydroalcoholic fraction of the same extract (Fig. 2C).

In general, similar sets of signals were observed in the two spectra. With the exception of the signals that are related to triglycerides, which were observed only in the spectrum of the dichloromethane fraction, the groups of signals observed confirm the presence of alkaloids and acetogenins in the two active fractions. Signals were also observed with a chemical shift that ranged between 3.7 and $3.9 \mathrm{ppm}$, which are characteristic of the methoxyl and/or carboxymethyl groups that are commonly found as a substitute in the skeletons of isoquinoline alkaloids. These groups may be related to the hydrogen of the methine groups in the alkyl chain of acetogenins that are connected directly to hydroxyl groups or epoxy groups. Moreover, signals with chemical shifts that ranged between 2.1 and $2.4 \mathrm{ppm}$, indicating the presence of $\alpha$-lactonyl and/ or $\alpha$-carbonyl hydrogens, suggesting the presence of acetogenins with ketone groups as substitutes in the alkyl chain, and signals with chemical shifts that ranged between 1.2 and $1.8 \mathrm{ppm}$, which are characteristic of the methylene groups and terminal methyl groups of these chains, were also observed in the spectra.

Table 4

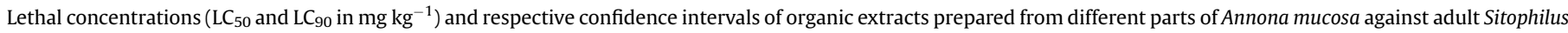

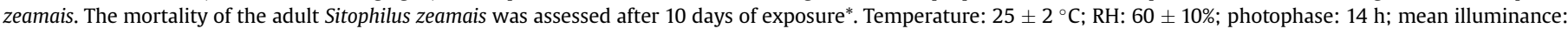
172 lux.

\begin{tabular}{|c|c|c|c|c|c|c|c|}
\hline Plant part & Solvent & $n^{\mathrm{a}}$ & Slope $( \pm$ SE) & $\chi^{2 \mathrm{~b}}$ & d.f. $^{c}$ & \multicolumn{2}{|c|}{$\mathrm{LC}(\mathrm{CI})^{\mathrm{d}}\left(\mathrm{mg} \mathrm{kg}^{-1}\right)$} \\
\hline Leaves & Hexane & 1200 & $6.34 \pm 0.42$ & 5.19 & 3 & $\begin{array}{l}\mathrm{LC}_{50} \\
\mathrm{LC}_{90}\end{array}$ & $\begin{array}{l}657.75(588.57-724.98) \\
1047.15(927.63-1259.46)\end{array}$ \\
\hline Seeds & Hexane & 1200 & $3.45 \pm 0.28$ & 5.42 & 3 & $\begin{array}{l}\mathrm{LC}_{50} \\
\mathrm{LC}_{90}\end{array}$ & $\begin{array}{l}110.28(62.91-146.79) \\
259.31(187.95-635.61)\end{array}$ \\
\hline Seeds & Dichloromethane & 1200 & $2.82 \pm 0.16$ & 5.56 & 3 & $\begin{array}{l}\mathrm{LC}_{50} \\
\mathrm{LC}_{90}\end{array}$ & $\begin{array}{l}149.79(126.39-182.25) \\
425.15(317.76-669.72)\end{array}$ \\
\hline
\end{tabular}

\footnotetext{
a $n$ : number of tested insects.

b $\chi^{2}$ : calculated chi-squared value.

c d.f.: degrees of freedom.

d CI: $95 \%$ confidence interval.
} 
A

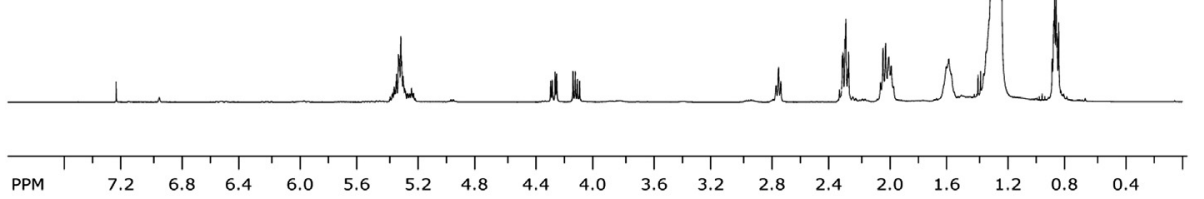

B

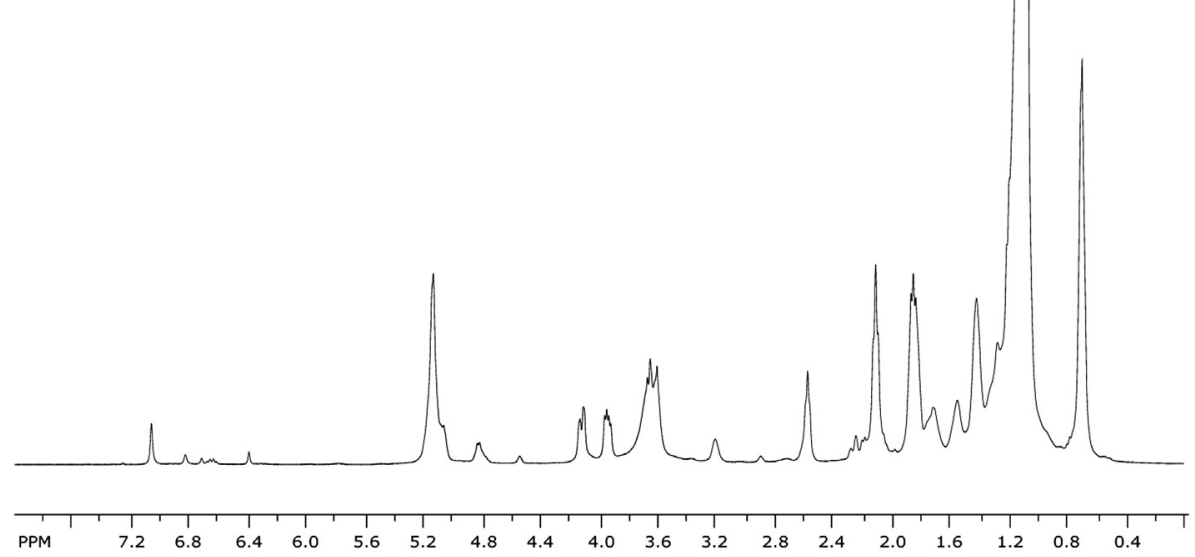

C

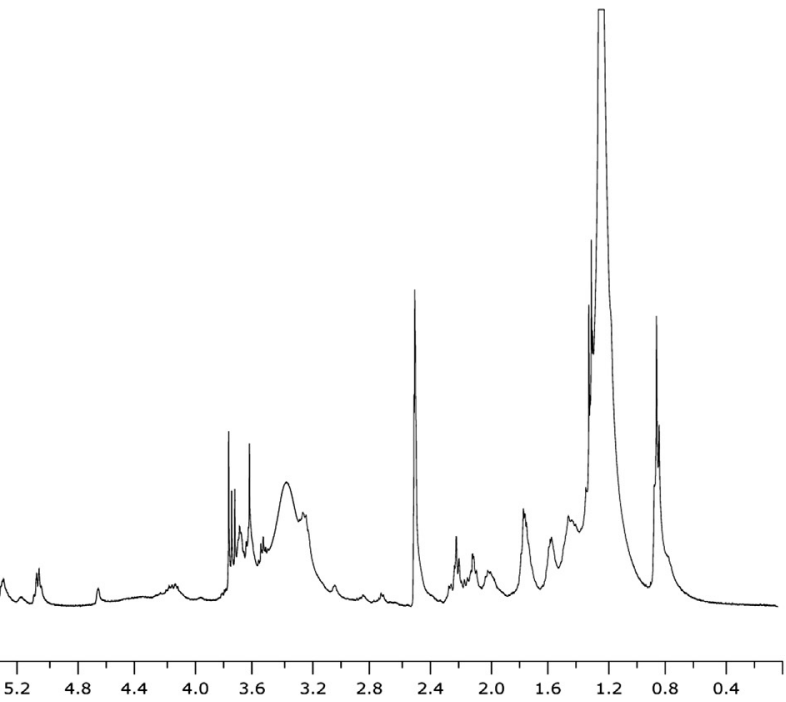

Fig. 2. ${ }^{1} \mathrm{H}$ NMR spectra of the hexane (A), dichloromethane (B), and hydroalcoholic (C) fractions of the extract prepared from the seeds of Annona mucosa in hexane. 


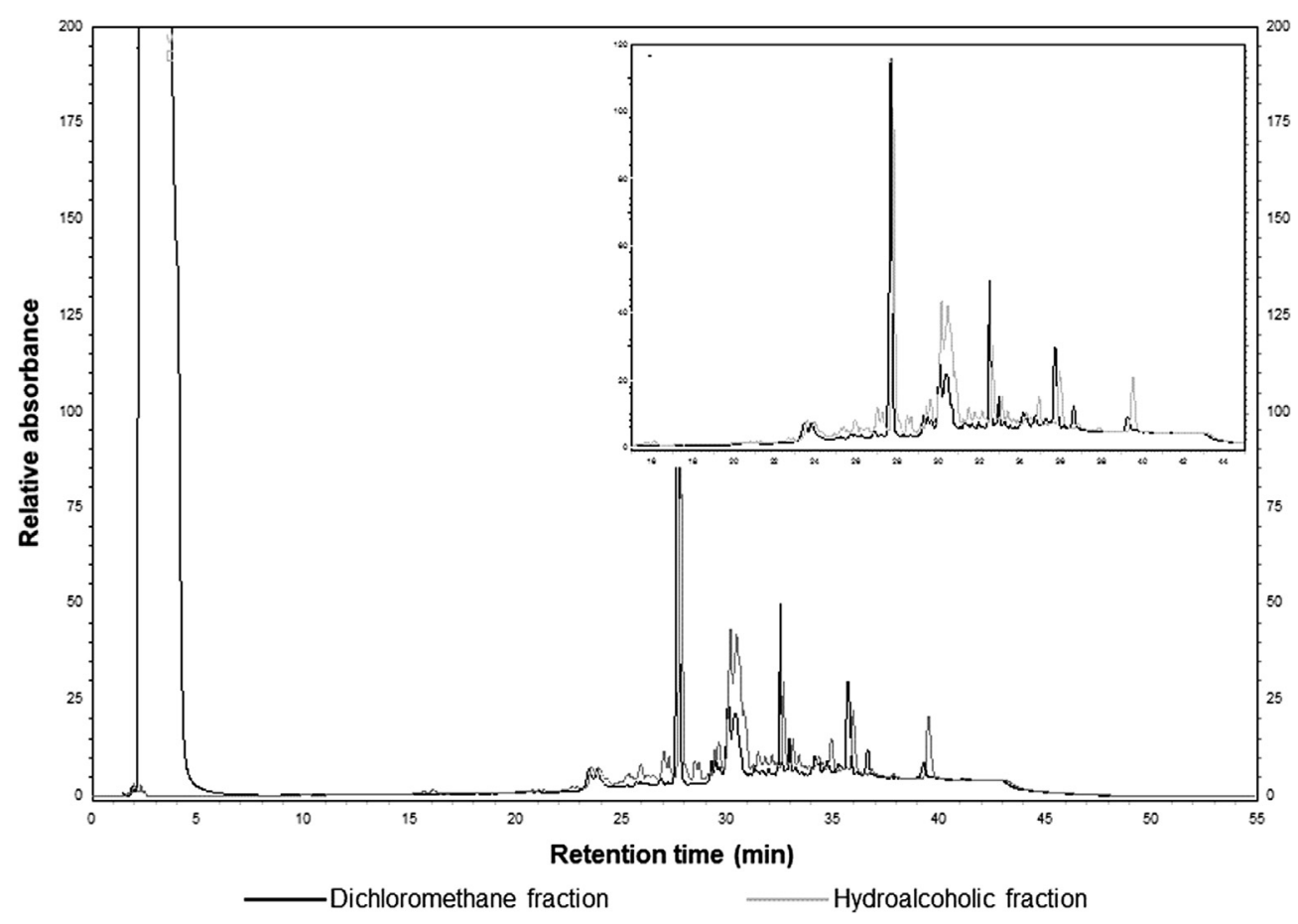

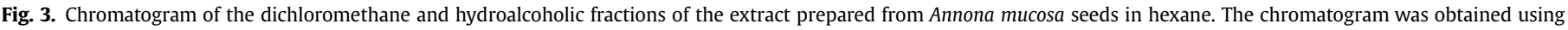
high-performance liquid chromatography (HPLC).

\section{Discussion}

The present study reports for the first time the pronounced biological activity of the compounds (allelochemicals) that are present in derivatives of $A$. mucosa against $S$. zeamais, a pest species associated with stored grain. There are no reports in the literature on the ecological interaction (insect-plant) between the species under study. Therefore, this finding supports the feasibility of screening for active compounds even in plants that occupy distinct ecological niches from the target insect pests and are thus not closely related to the host selection process or its defense against herbivory.

The high biological activity against $S$. zeamais of the A. mucosa extracts, especially those obtained from the seeds, is likely due to the great diversity and concentration of allelochemicals, particularly acetogenins and/or alkaloids, in the extract. The presence of allelochemicals with potent biological activities is a peculiar characteristic of plant species found in tropical environments (Coley and Barone, 1996). In fact, Levin and York (1978) found that the toxicity of alkaloids obtained from tropical plants is higher than that of alkaloids obtained from temperate crop species. According to Jones and Firn (1991), the chemical diversity of secondary compounds is a major factor in the survival and evolutionary success of plant species that inhabit an environment that contains a large number of natural enemies (herbivores and pathogens), which are key factors in the evolutionary process of the chemical defenses of plants.

In this context, studies have proven that well-defended plants biosynthesize and accumulate a wide variety of secondary compounds in their structures (Jones and Firn, 1991; Hartmann, 1996; Castellanos and Espinosa-García, 1997; Wink, 2006; Bednarek and Osbourn, 2009). Thus, our findings reinforce the potential to extract compounds associated with the secondary metabolism of diverse species of tropical flora to ultimately identify biologically active substances, including new active ingredients that can be used to protect stored grain against the harmful action of insect pests, which is an eminent need in the development of integrated pest management programs.

Traditionally, the plant structures of some species of Annonaceae have been used as botanical insecticides through homemade preparations, especially on small farms in developing and underdeveloped countries (Secoy and Smith, 1983; Okonkwo, 2005; Castillo et al., 2010). Since the 1980s, this botanical family has generated increasing attention due to the discovery of acetogenins, which exhibit a wide range of biological activities, including anthelmintic, antimalarial, antimicrobial, antiprotozoal, and pesticidal activities, and are toxic to tumor cells (Correa and Bernal, 1989; Alali et al., 1999; Ocampo and Ocampo, 2006).

Acetogenins comprise a number of natural products that are derived from fatty acids, contain between 32 and 34 carbons in

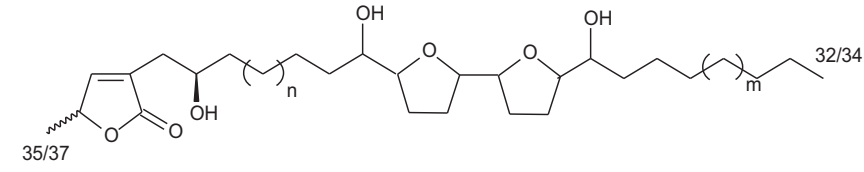

(a)

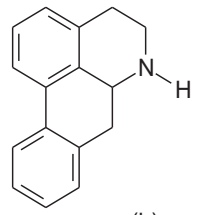

(b)

Fig. 4. General structure of acetogenins (a) and isoquinoline alkaloids (b) that are commonly found in species of the Annonaceae family. 
their structure, and have $\gamma$-lactone units at the ends of their alkyl chains. Several oxygenating compounds, such as hydroxyl groups, ketones, epoxides, tetrahydrofurans, and tetrahydropyrans, as well as double and triple bonds, may be present along the chain (Bermejo et al., 2005).

Acetogenins are potent inhibitors of complex I (NADH:ubiquinone oxidoreductase) in the mitochondrial electron transport systems and NADH:oxidase in the plasma membrane. These compounds also induce apoptosis (programmed cell death) likely as a result of the deprivation of ATP (Tormo et al., 1999), which is reflected in their potent bioactive effects against various species of insects (Cólom et al., 2008). Blessing et al. (2010) analyzed the incorporation of acetogenins in the diet of Spodoptera frugiperda (Lepidoptera: Noctuidae) and observed morphological changes to the larvae and pupae that are typical of compounds that interfere with the hormonal activity of Lepidoptera. Thus, it is possible to hypothesize that the biological activity of acetogenins on insects may be due to their action on different target sites, as observed with the limonoid azadirachtin, which was isolated from the seeds of Azadirachta indica (Meliaceae) (Mordue (Luntz) and Nisbet, 2000). This hypothesis seems reasonable for molecules with a large number of carbons in their structure and with various functional groups. However, further studies are necessary to elucidate the possible mechanism(s) and method(s) of action by which acetogenins affect insects.

Like acetogenins, the isoquinoline alkaloids, a class of compounds that is characteristic of Annonaceae, are commonly associated with plant defense against herbivorous insects (Da Rocha et al., 1981; Cordell et al., 2001; Bermejo et al., 2005; Cólom et al., 2009). The mode of action of alkaloids on insects is mainly related to their interaction with neural signal transduction networks, particularly through interference in the neuroreceptors, and their interaction with the enzymes involved in the neurotransmission metabolism and with ion channels (Wink et al., 1998; Wink, 2000). Despite the large diversity of alkaloids in Annonaceae and the potential biological activities of this class of compounds, there are no studies available on the biological activities of these compounds against insect pests of agricultural importance. However, some studies have evaluated the effects of these compounds against pests of medical importance. For example, Kabir (2010) found that the alkaloidal fraction of the extract of the branches of an Indian species of Annonaceae (Artabotrys odoratissimus) exhibits promising larvicidal effects against the mosquito Culex quinquefasciatus Say (Diptera: Culicidae).

Our results demonstrate a profound difference in the bioactivities of the extracts that were prepared using different parts of A. mucosa. These differences are likely due to qualitative and/or quantitative variations in the biosynthesis and the accumulation and/or distribution of the compound throughout the plant. This analysis should be linked to the strategy that the species uses to ensure the survival of both the individual through the maintenance of the photosynthetically active area and, primarily, of the progeny through the chemical protection of the seeds.

Some reports on the bioactivity of extracts from other species of the Annona genus on the insect pests of stored grain confirm the promising results described here. In all of the available studies, the most active extracts were obtained from seeds, and the activity levels depended on the concentration used and the solvent that was used to prepare the extract. Ohsawa et al. (1990) obtained promising results for the control of Callosobruchus chinensis (L.) (Coleoptera: Bruchidae) through the use of seed extracts from Annona squamosa that were prepared in petroleum ether. Rao et al. (2005) found that the hexane and ethyl acetate extracts of A. squamosa seeds are lethal to the third-instar larvae of Trogoderma granarium Everts (Coleoptera: Dermestidae) and induce changes in the growth and development and the cessation of feeding. Moreover, Llanos et al. (2008) obtained effective control of exposed $S$. zeamais weevils and the complete inhibition of the F1 progeny through the use of extracts from Annona muricata seeds, which were obtained with the use of hexane and ethyl acetate, at concentrations exceeding $2500 \mathrm{ppm}$.

According to our results, the extracts of $A$. mucosa may constitute promising grain protectors. These extracts may be applied through the formulation of a bioinsecticide using mainly the seeds of the plant, which are discarded by fruit-processing industries. In addition, the isolation and elucidation of the chemical structures of the active compounds (acetogenins and/or alkaloids) that are present in the more apolar extracts of $A$. mucosa seeds may enable the synthesis of new and more socially acceptable products through the use of model prototypes that are derived from natural products. However, despite the promising results, further studies are needed to both evaluate the toxicological action of these compounds on non-target organisms, mainly for human health, and to assess their biodegradability under environmental conditions, which are important aspects to be known before their recommendation. Furthermore, studies on the structure-activity relationship may also facilitate biotransformation assays aimed at the enhancement and/or expansion of the range of activities of these compounds and the minimization of any potential inconveniences.

\section{Acknowledgments}

The authors thank Drs. Renato Mello-Silva (Institute of Biosciences, University of São Paulo) and Heimo Rainer (Department of Systematics and Evolution of Higher Plants, University of Vienna) for their help in identifying the plant species that were studied. The authors also acknowledge the São Paulo Research Foundation (FAPESP) and the Brazilian National Council for Scientific and Technological Development (CNPq) for their financial support.

\section{References}

Adams, J.M., Schulten, G.G.M., 1976. Losses caused by insects, mites and microorganisms. In: Harris, K.L. Lindblad, C.J. (Eds.), Postharvest Grain Loss Assessment Methods, pp. 83-93. Slough, England.

Alali, F.Q., Liu, X.X., McLaughlin, J.L., 1999. Annonaceous acetogenins: recent progress. Journal of Natural Products 62, 504-540.

Araújo, R.A., Williamson, M.S., Bass, C., Field, L.M., Duce, I.R., 2011. Pyrethroid resistance in Sitophilus zeamais is associated with a mutation (T929I) in the voltage-gated sodium channel. Insect Molecular Biology 20, 437-445.

Basavaraja, H., Mahajanashetti, S.B., Udagatti, N.C., 2007. Economic analysis of postharvest losses in food grains in India: a case study of Karnataka. Agricultural Economics Research Reviews 20, 117-126.

Bednarek, P., Osbourn, A., 2009. Plant-microbe interactions: chemical diversity in plant defense. Science 324, 746-748.

Bermejo, A., Figadére, B., Zafra-Polo, M.C., Barrachina, I., Estornell, E., Cortes, D., 2005. Acetogenins from Annonaceae: recent progress in isolation, synthesis and mechanisms of action. Natural Products Reports 22, 269-303.

Blessing, L.T., Colom, O.A., Popich, S., Neske, A., Bardon, A., 2010. Antifeedant and toxic effects of acetogenins from Annona montana on Spodoptera frugiperda. Journal of Pest Science 83, 307-310.

Boyer, S., Zhang, H., Lemperiere, G., 2012. A review of control methods and resistance mechanisms in stored-product insects. Bulletin of Entomological Research 102, 213-229.

Braga, L.S., Corrêa, A.S., Pereira, E.J.G., Guedes, R.N.C., 2011. Face or flee? Fenitrothion resistance and behavioral response in populations of the maize weevil, Sitophilus zeamais. Journal of Stored Products Research 47, 161-167.

Caetano, C., Dadoun, H., 1987. Pallidine and aporphinoid alkaloids from Rollinia mucosa. Journal of Natural Products 50, 330

Castellanos, I., Espinosa-García, F.J., 1997. Plant secondary metabolite diversity as a resistance trait against insects: a test with Sitophilus granarius (Coleoptera: Curculionidae) and seed secondary metabolites. Biochemical Systematics and Ecology 25, 591-602.

Castillo, L.E., Jimenez, J.J., Delgado, M.A., 2010. Secondary metabolites of the Annonaceae, Solanaceae and Meliaceae families used as biological control of insects. Tropical and Subtropical Agroecosystems 12, 445-462.

Chang, F.R., Yang, P.Y., Lin, J.Y., Lee, K.H., Wu, Y.C., 1998. Bioactive kaurane diterpenoids from Annona glabra. Journal of Natural Products 61, 437-439. 
Chatrou, L.W., Rainer, H., Maas, P.J.M., 2004. Annonaceae (Soursop family). In: Smith, N., et al. (Eds.), Flowering Plants of the Neotropics. New York Botanical Garden, New York, pp. 18-20.

Chávez, D., Acevedo, L.A., Mata, R., 1998. Jimenezin, a novel annonaceous acetogenin from the seeds of Rollinia mucosa containing adjacent tetrahydrofurantetrahydropyran ring systems. Journal of Natural Products 61, 419-421.

Chávez, D., Acevedo, L.A., Mata, R., 1999. Tryptamine derived amides and acetogenins from the seeds of Rollinia mucosa. Journal of Natural Products 62, 11191122.

Chen, Y.Y., Chang, F.R., Wu, Y.C., 1996. Isoquinoline alkaloids and lignans from Rollinia mucosa. Journal of Natural Products 59, 904-906.

Cloyd, R.A., 2004. Natural indeed: are natural insecticides safer and better than conventional insecticides? Illinois Pesticide Review 17, 1-3.

Coley, P.D., Barone, J.A., 1996. Herbivory and plant defenses in tropical forests. Annual Review of Ecology and Systematics 27, 305-335.

Cólom, O.A., Barrachina, I., Mingol, I.A., Mass, C.G., Sanz, P.M., Neske, A., Bardon, A. 2008. Toxic effects of annonaceous acetogenins on Oncopeltus fasciatus. Journal of Pest Science 81, 81-85.

Cólom, O.A., Neske, A., Chahboune, N., Zafra-Polo, M.C., Bardón, A., 2009. Tucupentol, a novel mono-tetrahydrofuranic acetogenin from Annona montana, as potent inhibitor of mitochondrial complex I. Chemistry \& Biodiversity 6, 335-340.

Cordell, G.A., Quinn-Beattie, M.L., Farnsworth, N.R., 2001. The potential of alkaloids in drugs discovery. Phytotherapy Research 15, 183-205.

Correa, J.E., Bernal, H.Y., 1989. Especies vegetales promisorias de los países del convenio Andrés Bello, Guadalupe, Bogotá, vol. 1, p. 500.

Da Rocha, A.I., Luz, A.I.R., Rodrigues, W.A., 1981. A presença de alcaloides em espécies botânicas da Amazônia. III - Annonaceae. Acta Amazonica 11, 537546.

Demétrio, C.G.B., Hinde, J., 1997. Half-normal plots and overdispersion. Glim Newsletter 27, 19-26.

Estrada-Reyes, R., Alvarez, A.L., Lopes-Rubalcava, C., Rocha, L., Heinze, G., Moreno, J., 2002. Lignans from leaves of Rollinia mucosa. Zeitschrift fur Naturforschung 57, 29-32.

Ferreira, M.G.R., Santos, M.R.A., Silva, E.O., Gonçalves, E.P., Alves, E.U., Bruno, R.L.A., 2010. Emergência e crescimento inicial de plântulas de biribá (Rollinia mucosa (Jacq.) Baill) (Annonaceae) em diferentes substrates. Semina: Ciências Agrárias 31, 373-380.

Figueiredo, S.F.L., Viana, V.R.C., Simões, C., Albarello, N., Trugo, L.C., Kaplan, M.A.C., 1999. Lignans from leaves, seedlings and micropropagated plants of Rollinia mucosa (Jacq.) Baill. - Annonaceae. Plant Cell, Tissue and Organ Culture 56, $121-124$.

Finney, D.J., 1971. Probit Analysis. Cambridge University Press, Cambridge, p. 31.

Gu, Z.M., Zhou, D., Lewis, N.J., Wu, J., Shi, G., Mclaughlin, J.L., 1997. Isolation of new bioactive annonaceous acetogenins from Rollinia mucosa guided by liquid chromatography/mass spectrometry. Bioorganic \& Medicinal Chemistry 5, 1911-1916.

Hartmann, T., 1996. Diversity and variability of plant secondary metabolism: a mechanistic view. Entomologia Experimentalis et Applicata 80, 177-188.

Hinde, J., Demétrio, C.G.B., 1998. Overdispersion: models and estimation. Computational Statistics \& Data Analysis 27, 151-170.

Hodges, R.J., Buzby, J.C., Bennett, B., 2010. Postharvest losses and waste in developed and less developed countries: opportunities to improve resource use. Journal of Agricultural Science 149, 37-45.

Isman, M.B., 2006. Botanical insecticides, deterrents, and repellents in modern agriculture and an increasingly regulated world. Annual Review of Entomology 51, 45-66.

Jones, C.G., Firn, R.D., 1991. On the evolution of plant secondary chemical diversity. Philosophical Transactions of the Royal Society of London 333, 273-280.

Kabir, K.E., 2010. Larvicidal effect of an alkaloidal fraction of Artabotrys odoratissimus (Annonaceae) bark against the filarial mosquito Culex quinquefasciatus (Diptera: Culicidae). International Journal of Tropical Insect Science 30, 167169.

Kim, H.K.K., Choi, Y.H., Verpoorte, R., 2010. NMR-based metabolomic analysis of plants. Nature Protocols 5, 536-549.

Kotkar, H.M., Prashant, S.M., Sangeetha, V.G.S.S., Shipra, R.J., Shripad, M.U., Maheshwari, V.L., 2001. Antimicrobial and pesticidal activity of partially purified flavonoids of Annona squamosa. Pest Management Science 58, 33-37.

Lazzari, S.M.N., Lazzari, F.A., 2009. Insetos-praga de grãos armazenados. In: Panizzi, A.R., Parra, J.R.P. (Eds.), Bioecologia e nutrição de insetos. Embrapa Informação Tecnológica, Brasília, pp. 667-732.

Leboeuf, M., Cavé, A., Bhaumik, P.K., Mukherjee, B., Mukherjee, R., 1980. The phytochemistry of the Annonaceae. Phytochemistry 21, 2783-2813.

Leora Software, 2003. Poloplus 1.0: Probit and Logit Analysis. Berkeley, 1 CD-ROM.

Levin, D.A., York Jr., B.M., 1978. The toxicity of plant alkaloids: an ecogeographic perspective. Biochemical Systematics and Ecology 6, 61-76.
Liaw, C.C., Chang, F.R., Wu, M.J., Wu, Y.C., 2003. A novel constituent from Rollinia mucosa, rollicosin, and a new approach to develop annonaceous acetogenins as potential antitumor agents. Journal of Natural Products 66, 279-281.

Llanos, C.A.H., Arango, D.L., Giraldo, M.C., 2008. Actividad insecticida de extractos de semilla de Annona muricata (Annonaceae) sobre Sitophilus zeamais (Coleoptera: Curculionidae). Revista Colombiana de Entomología 34, 76-82.

Mordue (Luntz), A.J., Nisbet, A.J., 2000. Azadirachtin form the neem tree Azadirachta indica: its action against insects. Anais da Sociedade Entomológica do Brasil 29 $615-632$.

Nelder, J.A., Wedderburn, R.W.M., 1972. Generalized linear models. Journal of the Royal Statistical Society 135, 370-384.

Ocampo, D., Ocampo, R., 2006. Bioactividad de la família Annonaceae. Revista Universidad de Caldas 5, 135-155.

Ohsawa, K., Kato, S., Honda, H., Yamamoto, I., 1990. Pesticidal active substances in tropical plants-insecticidal substance from the seeds of Annonaceae. Journal of Agricultural Science 34, 253-258.

Okonkwo, E.O., 2005. Plant materials used for controlling insect pests of stored products in Nigeria, Families Annonaceae, Piperaceae, and Rutaceae. Journal of Herbs, Spices and Medicinal Plants 11, 47-69.

Olayemi, F.F., Adegbola, J.A., Bamishaiye, E.I., Awagu, E.F., 2012. Assessment of postharvest losses of some selected crops in eight local government areas of Rivers State, Nigeria. Asian Journal of Rural Development 2, 13-23.

Pereira, C.J., Pereira, E.J.G., Cordeiro, E.M.G., Della Lucia, T.M.C., Tótola, M.R., Guedes, R.N.C., 2009. Organophosphate resistance in the maize weevil Sitophilus zeamais: magnitude and behavior. Crop Protection 28, 168-173.

Pettit, G.R., Cragg, G.M., Polonsky, J., Herald, D.L., Goswami, A., Smith, C.R., Moretti, C., Schimdt, J.M., Weisleder, D., 1987. Isolation and structure of rolliniastatin 1 from the South American tree Rollinia mucosa. Canadian Journal of Chemistry 65, 1433-1435.

Pimentel, M.A.G., Faroni, L.R.D.'A., Guedes, R.N.C., Sousa, A.H., Tótola, M.R., 2009 Phosphine resistance in Brazilian populations of Sitophilus zeamais Motschulsky (Coleoptera: Curculionidae). Journal of Stored Products Research 45, 71-74.

R Development Core Team, 2012. R: a Language and Environment for Statistical Computing. R Foundation for Statistical Computing, Vienna, Austria.

Rainer, H., 2007. Monographic studies in the genus Annona L. (Annonaceae): inclusion of the genus Rollinia A.ST.-HIL. Annalen Naturhistorischen Museums in Wien - Serie B 108, 191-205.

Rao, N.S., Sharma, K., Sharma, R.K., 2005. Antifeedant and growth inhibitory effects of seed extracts of custard apple, Annona squamosa against khapra beetle, Trogoderma granarium. Journal of Agricultural Technology 1, 43-54.

Ribeiro, L.P., 2010. Bioprospecção de extratos vegetais e sua interação com protetores de grãos no controle de Sitophilus zeamais Mots. (Coleoptera: Curculionidae). Dissertação (Mestrado em Entomologia) - Escola Superior de Agricultura "Luiz de Queiroz". Universidade de São Paulo, Piracicaba, p. 154.

Ribeiro, L.P., Costa, E.C., Karlec, F., Bidinoto, V.M., 2008. Avaliação da eficácia de pós inertes minerais no controle de Sitophilus zeamais Mots. (Coleoptera: Curculionidae). Revista da FZVA 15, 19-27.

Rofrano, G., Rossi, E., Cosimi, S., 2009. Monitoring of insecticide resistance status in some Italian populations of Tribolium spp. Tecnica Molitoria 60, 877-885.

Secoy, D.M., Smith, A.E., 1983. Use of plants in control of agricultural and domestic pests. Economic Botany 37, 28-57.

Shi, G., Koslowski, J.F., Schwedler, J.T., Wood, K.V., Macdougal, J.M., Mclaughlin, J.L., 1996. Muconin and mucoxin: additional nonclassical bioactive acetogenins from Rollinia mucosa. Journal of Organic Chemistry 61, 7988-7989.

Shi, G., MacDougal, J.M., McLaughlint, J.L., 1997. Bioactive annonaceous acetogenins from Rollinia mucosa. Phytochemistry 45, 719-723.

Tefera, T., 2012. Post-harvest losses in African maize in the face of increasing food shortage. Food Security 2, 267-277.

Tormo, J.R., Gallardo, T., González, M.C., Bermejo, A., Cabedo, N., Andreu, I. Estornell, E., 1999. Annonaceous acetogenins as inhibitors of mitochondrial complex I. Current Topics in Phytochemistry 2, 69-90.

Van Beek, T.A., Breteler, H., 1993. Phytochemistry and Agriculture. Clarendon Press, Oxford, p. 245.

Vendramim, J.D., Castiglioni, E., 2000. Aleloquímicos, resistência de plantas e plantas inseticidas. In: Guedes, J.C., Costa, I.D., Castiglioni, E. (Eds.), Bases e técnicas do manejo de insetos. Pallotti, Santa Maria, pp. 113-128.

Viegas Júnior, C., 2003. Terpenos com atividade inseticida: uma alternativa para o controle químico de insetos. Química Nova 26, 390-400.

Wink, M., 2000. Interference of alkaloids with neuroreceptors and ion channels. In: Rahman, X.A. (Ed.), Bioactive Natural Products. Elsevier, pp. 3-129.

Wink, M., 2006. Importance of plant secondary metabolites for protection against insects and microbial infection. Advances in Phytomedicine 3, 251-268.

Wink, M., Schmeller, T., Latz-Bruning, B., 1998. Modes of action of allelochemical alkaloids: interaction with neuroreceptors, DNA, and other molecular targets. Journal of Chemical Ecology 24, 1881-1937. 